\title{
Prognosis of radionuclid contamination spreading on the site of Temporary Waste Storage of RRC "Kurchatov Institute"
}

\author{
A. Rastorguev², K. Buharin², V. Volkov ${ }^{1}$, D. Tsurikov ${ }^{1}$, Yu. Zverkov $^{1}$, \\ I. Rastorguev ${ }^{1}$ and E. Volkova ${ }^{1}$ \\ ${ }^{1}$ Russian Research Centre "Kurchatov Institute", 1 Kurchatov Sq., 123182 Moscow, Russia \\ ${ }^{2}$ DAR/VODGEO, Komsomolsky pr-t, 42, Str. 2, 119992 Moscow, Russia
}

\begin{abstract}
In a period between 1943 and 1974 radioactive wastes were temporary buried on a special site on the territory of RRC "Kurchatov Institute". The site monitoring held since the end of the 80s showed that contaminants are located not only on the surface and in the ground but they have also spread in groundwater. The paper presents preliminary results of the work on development of numerical models of radioactive contamination migration the waste disposal site. The objectives of the work were to evaluate the existing contamination plume, to determine mechanisms of contaminant migration on the site and to develop a numerical model of radioactive contamination transport that would allow correctly predicting further plume spreading for making necessary engineering decisions. Based on laboratory findings and radiation monitoring data obtained at the waste disposal site and its adjacent areas, there were determined the site hydrogeological structure and parameters, and a geoinformation database was developed. Three-dimensional numerical models of groundwater flow (using the MODFLOW code) and mass transport (using the MT3DMS code) were built and verified against field measurements. Using these models, preliminary predictions of radionuclide migration from the waste disposal site were made.
\end{abstract}

\section{INTRODUCTION}

In the period between 1943 and 1974 radioactive wastes were buried in ten temporary repositories built on a specially allocated site at the RRC "Kurchatov Institute" territory. The site used for the temporary radwaste repositories has an area of about 2 hectares and is situated near the Kurchatov Institute external perimeter in the immediate vicinity to a city residential area [Ponomarev-Stepnoy et al., 2002].

Radioactive survey of the site and its adjacent areas performed in the late 1980s - early 1990s showed that radioactive contamination is present not only at the surface but has a tendency of spreading into groundwater.

To analyse and monitor radioactive contamination of groundwater, about a hundred exploration wells were drilled on the site, with 30 of them adapted for observations. As a result of the survey it was found that contamination of the soil is mainly connected with Sr-90 and Cs-137, and contamination of groundwater - with Sr-90. Since the radiation survey results have demonstrated the necessity to clean up the site, rehabilitation activities on radwaste removal and liquidation of old repositories have been conducted at the site since early 2001 [Volkov et al., 2003; Volkov et al., 2004].

In the period between 2002 and 2003 additional observation wells were drilled and equipped on the site and beyond its boundaries in order to extend the radiation monitoring zone, determine more precisely the character, direction and boundaries of possible radioactive contamination spreading in groundwater. At present time the monitoring network consists of about 30 observation wells, 21 of which control the upper moraine water-bearing horizon and 9 - the lower Jurrassic water-bearing horizon; this network is used for regular recording of groundwater levels, its chemical and radionuclide composition. 
In 2002 concurrently with the rehabilitation activities at the radwaste disposal site, development of a mathematical model of radioactive contamination spreading in groundwater was started. The objectives of this work are creation and maintenance of a geoinformation system for the site involved, evaluation of radioactive contamination plume existing at the site, determination of possible contaminant migration mechanisms and correct prediction of further contamination plume spreading that would provide a basis for engineering decision-making.

\section{CREATION AND MAINTENANCE OF THE GEOINFORMATION SYSTEM}

At the first stage of the work a special geoinformation system was developed; it reflects the condition of underground hydrosphere at the radwaste disposal site and in adjoining areas. The system was made up of two databases: a cartographical one (implemented in the MapInfo geoinformation system environment), and a text/numerical one (implemented in the Microsoft Access environment). The following information about the site under study was recorded in the databases: a layout of old repositories, a plan of utility lines, a map of monitoring and exploration wells, data on heads in wells and lithological composition of the area, and results of radiochemical analyses of core material samples. Following adjustments to the databases, results of observations and laboratory tests were analysed. Unfortunately, the observations were not continuous: the data are available for the period from the late 1991 to mid 1995, and from 2000 to the present time, as the majority of wells were drilled only in 2002-2003.

\section{DESCRIPTION OF LEVEL CONDITIONS AND CHARACTERIZATION OF FLOW AND TRANSPORT PARAMETERS}

Examination of historical records allowed concluding that in 1976 the groundwater levels in two upper water-bearing horizons at the radwaste disposal site were on the average 3 meters below the currently observed levels. Analysis of the data showed that in the period between the early 1988 and late 1991 there was an abrupt increase in the level of the upper moraine water-bearing horizon that was likely due to leakage from the city sewer that crosses the radwaste disposal site. It should be noted that, according to the observation data, a peak of Sr-90 activity in groundwater occurred in 1993 (Fig. 1). This is likely to result from the raise in the level of the upper moraine water-bearing horizon and consequent water invasion to the temporary radwaste repositories.

The monitoring data allow us to believe that at present the both water-bearing horizons are in nearly steady-state conditions. Based on the analysis results, there exists a general tendency towards recession of horizon levels that is favourable to condition of the old repositories situated on the site as it reduces the risk of their repeated underflooding.

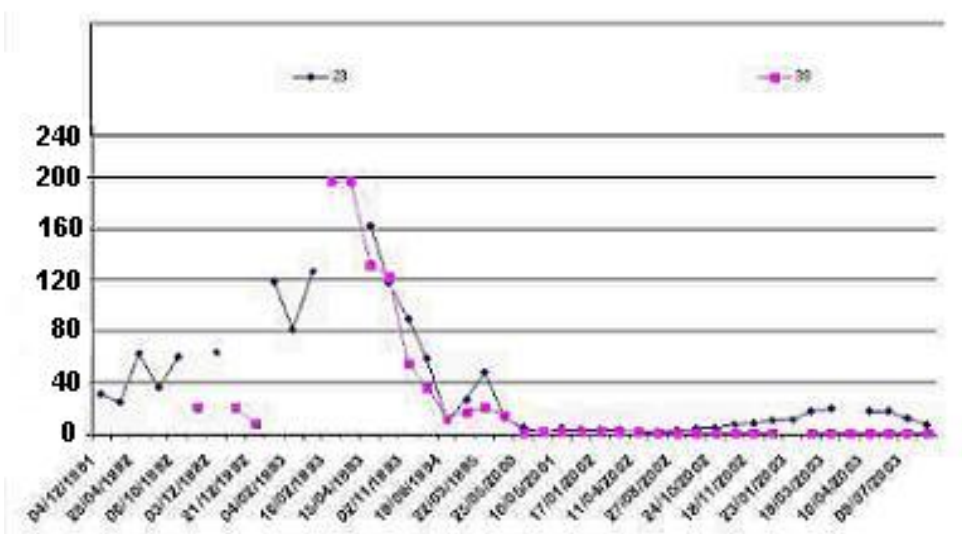

Figure 1. Sr-90 concentration curve for groundwater of the upper moraine water-bearing horizon, wells 23 and 38 (in relative units). 


\section{MODEL DEVELOPMENT}

The work on development and creation of a mathematical model of radioactive contamination spreading with groundwater that would allow evaluating the existing contamination plume, clarifying contamination transport mechanisms and predicting the plume spreading was started in 2002.

In view of the importance of the subject of study, when developing the mathematical model of radioactive contamination spreading an attempt was made to take into account all data obtained from the monitoring and drilling activities. The basic hydrogeological and technogenic conditions of the site involved where the old repositories are located can be implemented on the basis of the 3-dimentional convective-dispersion transport model taking into account sorption and radioactive decay. The model calculations were performed with the MODFLOW and MT3DMS codes that are most widely used today for solution of practical problems connected with consumption and protection of groundwater.

In order to provide a detailed description of facilities located at the radwaste disposal site, there was used a uniform planar discretization with a step of $2 \times 2 \mathrm{~m}$ and the model mesh oriented along the groundwater flow. Vertical discretization of the model was chosen in accordance with filtration and migration characteristics of water-bearing rock and the pattern of groundwater contamination. Eight layers were singled out.

Calculated parameters of the flow and migration models - permiability coefficients of different layers, infiltration, possible locations of leakage from the city sewer, sorption, porosity and dispersivity parameters - were obtained as a result of the model verification against observations, field and laboratory experiments, as well as through the use of geostatistical analysis methods. Special attention was paid to determining contamination sources. There are ten old repositories at the disposal site that differ in design and composition of wastes they contain. No historical records on the wastes are available, and it is uncertain which of them were partially drowned during the groundwater level elevation in 1993 and to what extent. In this connection contamination sources and migration parameters were set during the modelling such that the Sr-90 concentration curve obtained fitted the curves plotted from the most representative observation well data.

\section{PREDICTION RESULTS}

Predictions of migration of radioactive contamination with Sr-90 were performed for two alternative scenarios of rehabilitation activities: a) accident-free radwaste removal and liquidation of old repositories (Fig. 2a); b) the repositories are not removed with possible elevation of the upper moraine horizon level, resulting in watering of the repositories and additional contamination of groundwater (Fig. 2b). The predictions allow concluding that in case of the accident-free waste removal and liquidation of the old repositories, the contamination plume containing Sr-90 in excess of the manageable level will be kept within the boundaries of the site under study over the next 100 years. But there is still a possibility for further elevation of the upper moraine water-bearing horizon level and consequent watering of the old repositories. In this case (Fig. 2b), as a result of radioactive contamination migration into groundwater, the contamination plume containing Sr-90 in excess of the manageable level may further spread and move outside the site. 

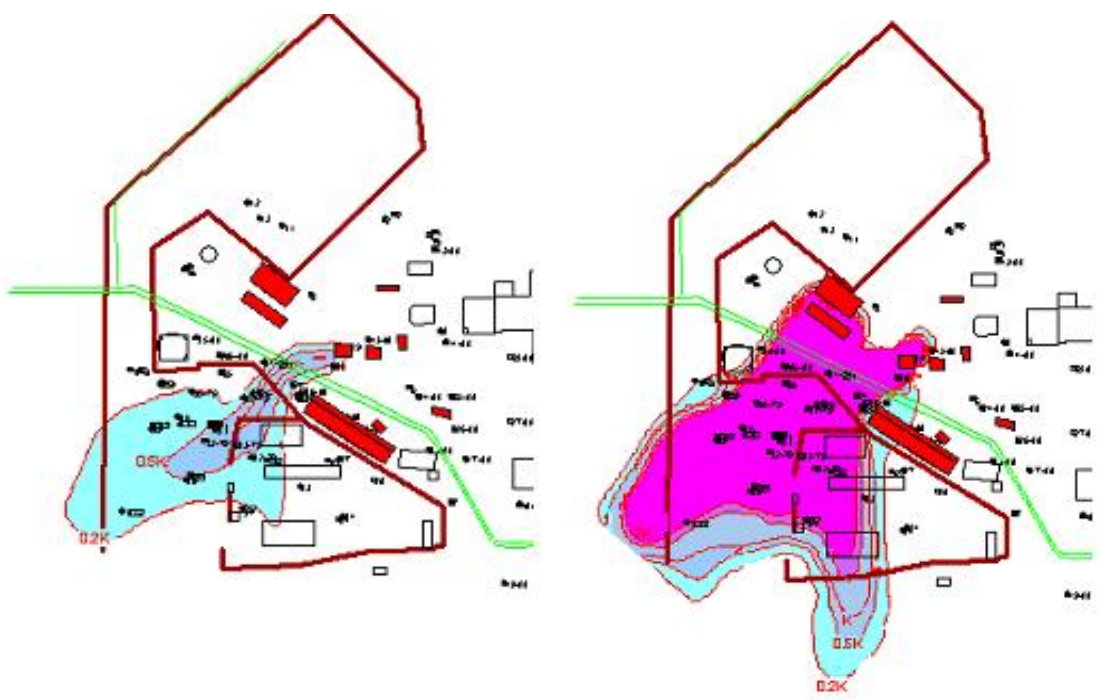

Figure 2. Prediction of Sr-90 spreading for the year 2025: a - the case of complete removal of the old repositories and contaminated soil; $\mathbf{b}$-the case of repeated watering of the repositories without their removal ( $\mathrm{K}$ - contamination level, relative units).

\section{CONCLUSIONS}

The performed analysis of historical records and monitoring data allowed defining the sources of groundwater contamination more precisely and determining hydrogeological characteristics of the object of investigation - the RRC "Kurchatov Institute” radwaste disposal site and its adjacent areas. Preliminary predictions of radionuclide migration from the site involved performed for the next 100 years demonstrated efficiency of the measures taken for rehabilitation of the contaminated area and liquidation of the old repositories. If said rehabilitation activities are not completed, there is a possibility that the upper moraine water-bearing horizon level would further rise, which will lead to additional migration of radioactive contamination into groundwater and further spreading of contamination plume containing Sr-90 in excess of the action level beyond the site under study.

The data and numerical models obtained can be further used to substantiate selection of remediation measures or engineering systems for protection of the adjacent territory from radioactive contamination spreading.

\section{References}

[1] Ponomarev-Stepnoy N.N., Volkov V.G., Kucharkin N.E. et al. "Rehabilitation of Radioactively Contaminated Facilities and the Site of Russian Research Centre “Kurchatov Institute”, IBC's 8th International Conference \& Exhibition on Decommissioning of Nuclear Facilities - Managing the Legacy, London, Great Britain, November 11-12, 2002 (EA1141, IBC Global Conferences) pp.

[2] Volkov V.G., Ponomarev-Stepnoy N.N., Melkov E.S. et al. "Status of Activities on Rehabilitation of Radioactively Contaminated Facilities and the Site of Russian Research Centre "Kurchatov Institute”, WM’03 Conference, Tucson, Arizona, USA, February 23-27, 2003 (WM Symposia Inc.)

[3] Volkov V.G., Ponomarev-Stepnoy N.N., Gorodetsky G.G. et al. “The First Stage of Liquidation of Temporary Radwaste Repositories and Rehabilitation of the Radwaste Disposal Site at the Russian Research Centre "Kurchatov Institute”, WM'04 Conference, Tucson, Arizona, USA, February 29 - March 4, 2004 (WM Symposia Inc.) 